\title{
Relief Presentation on US National Park Service Maps
}

\author{
Tom Patterson ${ }^{\mathrm{a}}$ \\ ${ }^{a}$ Harpers Ferry Center, National Park Service, Harpers Ferry, West Virginia, US; tom_patterson@nps.gov
}

\begin{abstract}
This paper examines the evolution of relief presentations on maps developed by Harpers Ferry Center, the media service center of the US National Park Service (NPS). Harpers Ferry Center produces the maps used by park visitors. I will discuss five park maps, each with a distinctive relief style and mode of production. They appear in rough chronological order of their development. Recent relief presentations are generally more detailed, colorful, and realistic than those from earlier years. Changing technology is largely responsible for the different relief styles found on park maps. Some relief treatments today were not possible, or imaginable, in 1977 when the NPS established the brochure program in its modern phase. Landscape heterogeneity is another factor behind the development of different relief styles. With over 400 park sites ranging from the glacial mountains of Alaska to the rolling piedmont of Virginia, a onestyle-fits-all approach cannot adequately depict all landscapes. NPS maps serve some 300 million park visitors each year. Our ongoing effort to make understandable maps for this diverse audience has further spurred experiments in relief presentation.
\end{abstract}

Keywords: shaded relief, park maps, natural color, texture shading, rock textures, geospatial images

\section{Introduction}

This paper examines the evolution of relief presentations on maps developed by Harpers Ferry Center, the media service center of the US National Park Service (NPS). Harpers Ferry Center produces standardized "Unigrid" bro-chures, which include the maps used by park visitors. What follows is a general overview of five park maps, each with a distinctive relief style and mode of production. They appear in rough chronological order of their development. Recent relief presentations are generally more detailed, colorful, and realistic than those from earlier years.

Changing technology is largely responsible for the different relief styles found on park maps. Some relief treatments today were not possible, or imaginable, in 1977 when the NPS established the brochure program in its modern phase. Landscape heterogeneity is another factor behind the development of different relief styles. With over 400 park sites ranging from the glacial mountains of Alaska to the rolling piedmont of Virginia, a one-style-fits-all approach cannot adequately depict all landscapes. NPS maps serve some 300 million park visitors each year. Our on-going effort to make understandable maps for this diverse audience has further spurred experiments in relief presentation.

The relief presented on NPS maps is generally not as important as visitor information: points of interest, facilities, roads, trails, etc. To reflect this context, the relief examples that follow are excerpts from published park maps containing all classes of information. They are also exclusively planimetric, since delving into the intricacies of $3 \mathrm{D}$ relief presentation is well beyond the scope of one paper.

\section{Manual Shaded Relief}

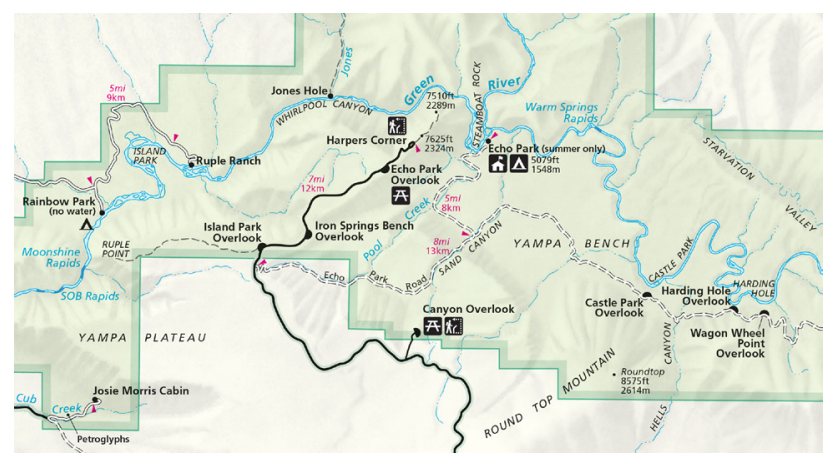

Fig. 1. Dinosaur National Monument, Utah and Colorado, featuring an airbrushed shaded relief by Bill von Allmen, 1983.

Over 35 years ago when the NPS Unigrid program launched, one of the main goals was to bring park maps out of "the dark ages of line-work cartography" according to Vincent Gleason, then Chief of Publications (Hanna, 1988). His vision was to represent terrain on maps with user-friendly shaded relief instead of hachuring or contour lines. Under Gleason's guidance, RR Donnelley Cartographic Services, the firm hired to develop park maps with an entirely new look, produced the first shaded relief maps. Soon afterwards, the NPS tapped cartographer Bill von Allmen (1928-2013) to be the inhouse shaded relief artist (Figure 1). He spent six weeks training at the Swiss Federal Office of Topography (now called swisstopo), and then went on to produce over 80 shaded reliefs before retiring in 1990. Tom Patterson, hired in 1992 to replace von Allmen, hand-drew 12 reliefs prior to switching to digital production in the mid1990s. Examples from both artists are available on the Shaded Relief Archive website (see references for URL).

Von Allmen's tool of choice was the Paasche AB airbrush, with which he sprayed a mist of ink on Metalmount, a brand of paper adhered to an aluminum 
sheet for dimensional stability. He worked from contour lines applied to the Metalmount as a temporary blue emulsion. As a last step he would spray ammonia on the completed art to re-move the contours, without damaging the airbrush work. By comparison, Patterson drew reliefs with a $4 \mathrm{H}$ pencil on Dupont Cronaflex UC-4 drafting film. The rice starch surface on this film was receptive to smudging with stumps, finely pointed sticks made from rolled cardboard that absorb graphite. A contour base map could be read through the translucent drafting film. By sliding a white sheet of paper under the drafting film, Patterson could see the shaded relief he was drawing without the contour lines.

Regardless of the production method, creating manual shaded relief was slow and painstaking work. A large park relief could take one month to complete. Manual shaded relief often appears highly generalized because adding detail and refinement to the art requires even more time. Given the great effort that went into creating manual relief art, the natural tendency was to feature it prominently on early NPS maps, even if it interfered with other in-formation. Printing of the shaded relief became lighter on subsequent printings. On a typical map from that era the relief would print in black and combine with flat area colors built from cyan, magenta, and yellow. Halftone screen-printing would control shadow densities on the shaded relief, simulating continuous tones. The densest shadows were 15 percent black, flat areas 4 percent, and highlights 1 percent. Dinosaur National Monument is one of the few remaining NPS maps that still employ manual shaded relief (Figure 1), although a digital version will replace it in 2015.

Shaded reliefs created manually reflect individual artistic styles, and they vary in appearance (Figure 2). If an artist had to redraw a relief of the same area, the second version would look slightly different from the first. On the other hand, NPS shaded relief art exhibits common traits, regardless of who drew it. Modulated light and shadows create the impression of $3 \mathrm{D}$ terrain on a flat sheet of paper. The illumination source is from the northwest (upper left), and prominent features receive most emphasis.

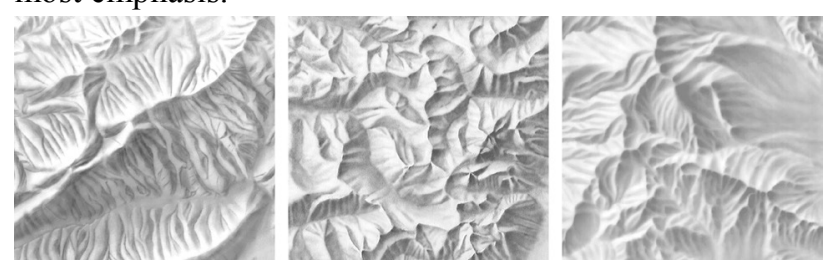

Fig. 2. Manual relief examples: (Left) Hot Springs National Park, Arkansas, by RR Donnelley. (Center) Grand Teton National Park, Wyoming, by Bill von Allmen. (Right) City of Rocks National Reserve, Idaho, by Tom Patterson.

\section{Digital Shaded Relief}

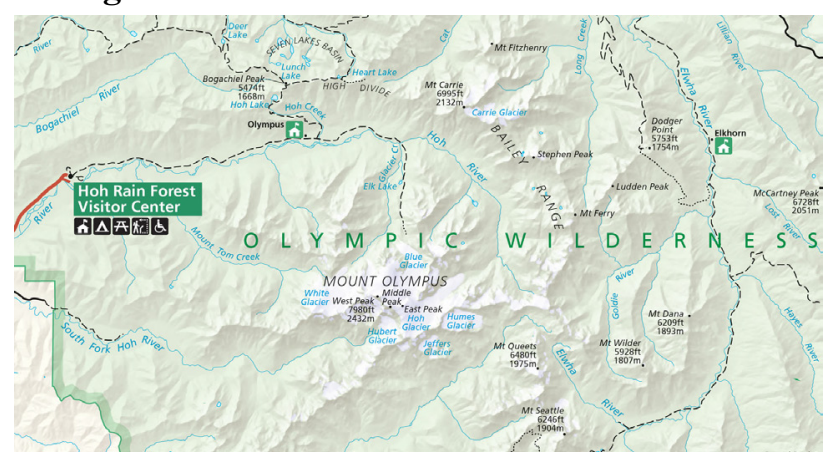

Fig. 3. Digital shaded relief of Olympic National Park, Washington.

The switch from manual to digital cartography starting in the 1990s revolutionized NPS shaded relief production. What had been the most difficult map element to produce eventually would become one of the easiest, reducing production time for a basic relief from a few weeks to a few minutes.

The switch to digital did not happen overnight. Inadequate software, lack of an integrated digital workflow, and poor or unavailable elevation data hampered early production efforts. For example, USGS digital elevation models (DEMs) from that time suffered from terracing and striping artifacts, which yielded ugly blemishes when rendered as a shaded relief. In addition, the valley bottoms were often out of registration with drainage lines. Using these flawed data to produce a barely acceptable shaded relief required hours of editing in Adobe Photoshop. It was of-ten more convenient to scan an old manual shaded relief for a new park map otherwise made from digital data. Nowadays the situation is much improved. The NPS uses Natural Scene Designer Pro software to efficiently produce shaded reliefs from artifact-free DEMs acquired from the USGS National Elevation Dataset.

The NPS initially presented digital relief on maps in the same manner as manual relief, lightly printing it as background black (Figure 3). In contrast to manual shaded relief, a frequent problem with digital relief is excessive detail (Figure 4). The DEMs from which the relief derives often contain more detail than that necessary on a visitor map, inadvertently producing visual noise. The NPS alleviates this problem by downsampling DEMs prior to rendering shaded reliefs, then applying the median filter to the rendered art afterwards in Photoshop. The median filter eliminates small terrain details while preserving the larger features. Terrain Sculptor software is another method used by the NPS to generalize DEMs before relief rendering takes place (Leonowicz et. al., 2010). The NPS completes a shaded relief by adding contrast at higher elevations to increase the apparent three-dimensionality of mountains. Using a grayscale DEM as a Photoshop layer mask and applying extra tone to mountaintop shadows accomplishes this enhancement. The aerial perspective effect developed for Swiss topographic maps is the basis for this technique (Imhof, 1982). 
A recent trend is to print digital relief in colors other than black. For instance, using light beige relief for a southwestern desert park evokes an arid environment. Beige relief also interferes less with black type and symbols, improving overall map legibility. Printing shaded reliefs in colors that mimic the natural environment introduces the next topic of this chapter, natural colors.
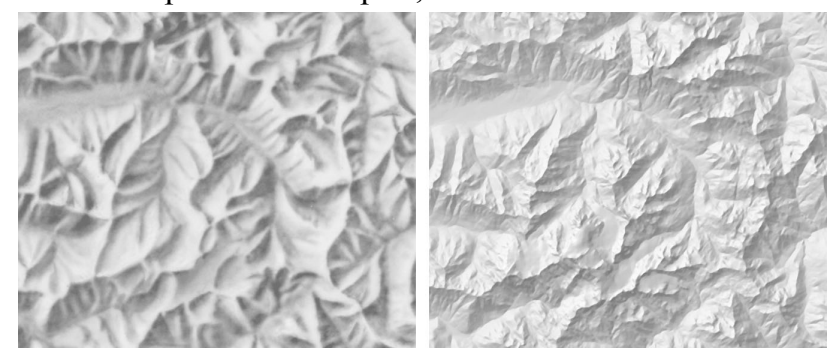

Fig. 4. Olympic National Park, Washington. (Left) Manual shaded relief created by Bill von Allmen. (Right) Digital shaded relief rendered from a 90-meter DEM.

\section{Natural Color}

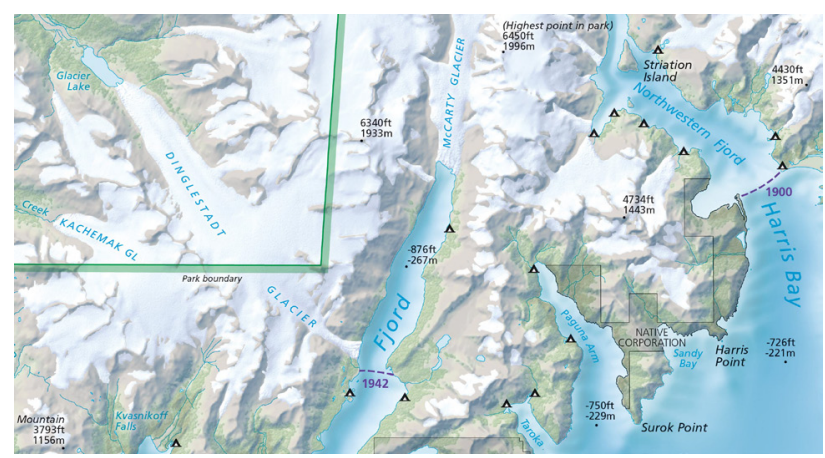

Fig. 5. Kenai Fjords National Park, Alaska, in natural color.

The popularization of natural color maps started with USGS cartographer Hal Shelton (1916-2004). Working on his own time, Shelton developed a series of route maps for airline passengers during the $1950 \mathrm{~s}$ and $60 \mathrm{~s}$, when air travel was first becoming commonplace (Patterson and Kelso, 2004). He believed that for his maps to be effective they should use colors resembling those that passengers could see on the ground below. With the assistance of a team of academic geographers who compiled land cover information on base maps (Earth monitoring satellites did not exist then), Shelton painted beautiful and realistic maps using a natural palette. If an area was coniferous forest, he painted it dark blue-green; if it was deciduous, medium green; grassland, light yellow-green; and so on.

Shelton's approach to mapping with colors found in nature seemed applicable to large expanses like Kenai Fjords National Park, Alaska (Figure 5). Unlike the traditional map of Dinosaur National Monument (Figure 1), which employs an arbitrary color choice, flat green, the varying colors on the Kenai Fjords map help users better understand land cover and the related natural environment.

Creating a natural color park map is accomplished with raster land cover data, such as National Land Cover Dataset (NLCD), available for the entire US at 30-meter resolution. Like painting by the numbers, but using pixels in-stead, the garish colors of the original land cover image are swapped for a new palette derived from nature (Figure 6). Landscape photographs available on popular online sites are a good source for appropriate natural colors - color selection is a simple matter of sampling them with the "eyedropper" tool in Photoshop. Subtle colors work best. In addition, at larger map scales, assigning organic textures to the land cover colors produces a more realistic appearance. For example, the Kenai Fjords map has subtle textures representing tree canopy and glacier surfaces. As a finishing touch, standard shaded relief illuminated from the northwest defines the topographic forms.

Natural color maps are a synthesis of satellite images and shaded relief maps. Although natural color maps often look realistic, they differ from aerial imagery by what they lack-haze, cast shadows, clouds, and unneeded photo-graphic detail (Patterson, 2002). They are essentially reconstituted satellite images optimized for cartographic depic-tion. Natural color maps are not without problems, however. The natural world can be disorganized and untidy, and so too are some natural color maps. If too highly textured and boldly printed, overall map legibility can suffer. And natural color maps do not combine well with arbitrary area colors representing land ownership. It is best to depict property parcels with simple bounding lines to avoid color confusion.
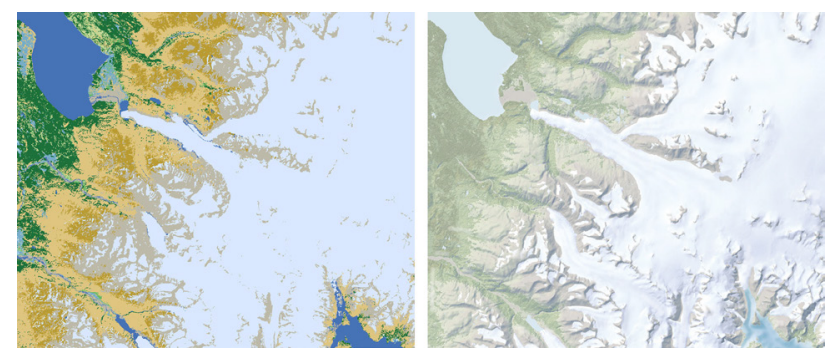

Fig. 6. Kenai Fjords National Park, Alaska. (Left) National Land Cover Dataset. (Right) Natural colors, textures, and shaded relief applied to National Land Cover Dataset.

\section{Texture Shading}

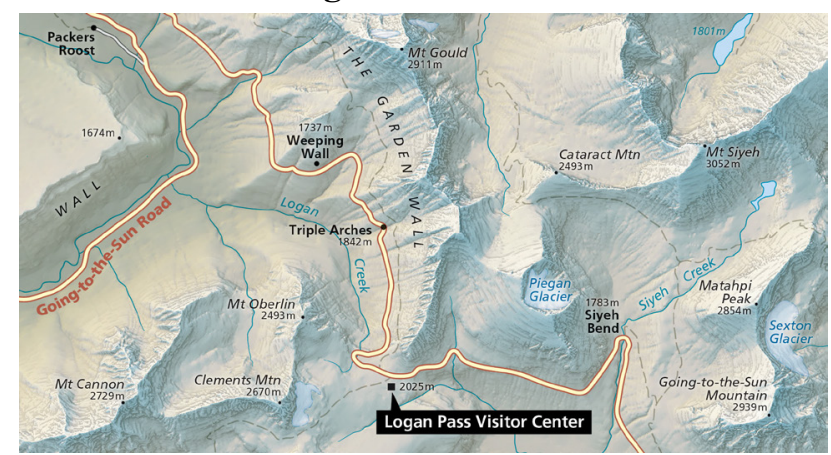

Fig. 7. Glacier National Park, Montana, with rock textures applied to steep slopes.

Texture shading has become a common element of NPS relief presentations since the 2010 introduction of the technique (Brown, 2014). Texture Shading is produced by Terrain Texture Shader, software that detects, amplifies, and renders slight variations in DEMs as 
images with increased contrast (Figure 8). By itself, texture shading is too dark and contrasting to have cartographic utility. But when merged with shaded relief-the recommended proportions are 60 percent shaded relief and 40 percent texture shading - it enhances the shaded relief. The addition of texture shading reveals subtle details on illuminated slopes and in flat areas not evident on the original shaded relief (Figure 9, center). The merged results have a flatter tonal range that works well as a background on maps filled with other tourist information, especially when the relief is lightened and colorized (Figure 9, right). Texture shading is most beneficial in low, irregular topography, like glacial deposits and eroded badlands.
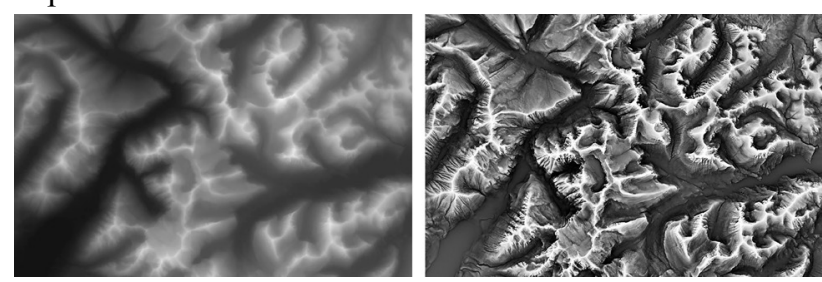

Fig. 8. Glacier National Park, Montana. (Left) A grayscale DEM. (Right) A texture shading created from the DEM at default settings.
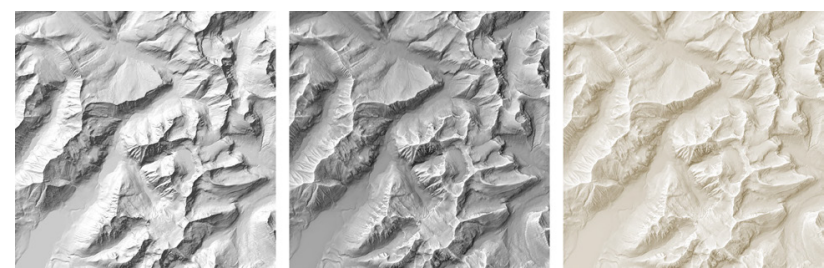

Fig. 9. Glacier National Park, Montana. (Left) Shaded relief (Center) Merged shaded relief and texture shading. (Right) The merged results lightened and colorized.

Mountain landscapes also can benefit from the texture shading technique, which can yield acceptable rock textures from DEMs under ideal situations (Patterson, 2014). Mountains with horizontal rock layers, such as those at Glacier National Park, Montana, are best suited to the technique (Figure 7). To produce rock textures, one first must render a texture shading with maximum detail and contrast. This visually noisy image is then combined with a shaded relief made from the same DEM in Photoshop, and with a slope layer mask to apply it only to the steepest slopes. Other enhancements to Glacier National Park map include green lowland hypsography in the deepest valleys, yellow sunlight on illuminated slopes, and complementary cool blue on shadowed slopes. Swiss topographic maps inspired the color scheme.

\section{Hybrid Geospatial Images}

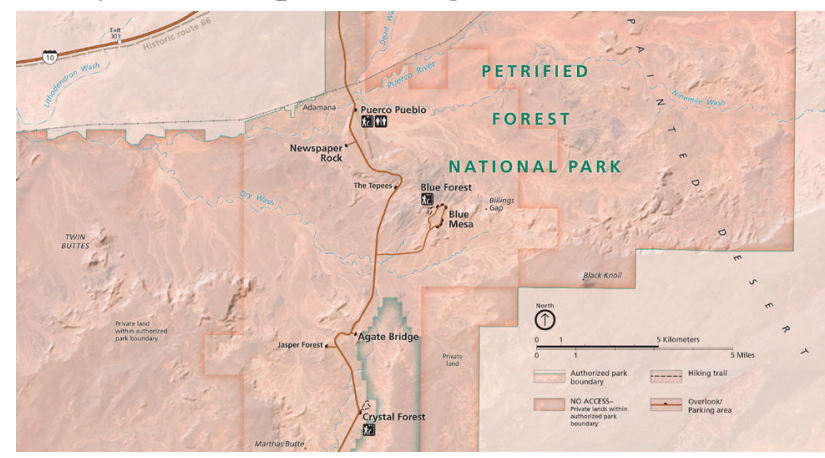

Fig. 10. Petrified Forest National Park, Arizona, featuring a Landsat 8 satellite image combined with shaded relief.

A growing trend on NPS maps is the integration of geospatial images-satellite images and aerial photographs - with relief presentations. The use of these images was at first sparing. For example, natural color maps were enhanced by selectively borrowing glacier and forest textures from aerial photographs. More recently, the NPS has be-gun using images as the dominant component in relief presentations (Figure 10). The increased number of sources for free image data has encouraged this experimentation. National Agricultural Imagery Program (NAIP) and Landsat 8 are the images used most often on NPS maps.

Using geospatial images in relief presentations works best on landscapes with low relief, such as lava flows, braided rivers, marshes, shallow water bodies, and deserts. For example, the map of Petrified Forest National Park, Arizona (Figure 10) uses Landsat 8, which captures the rich colors of the Painted Desert and a network of dry streambeds. It gives a truer picture of that desert environment beyond what is possible with traditional cartography. Depicting the many dry streams with conventional blue lines, for example, would imply more water than what normally exists.

Landscapes with low relief have another advantage on geospatial images: fewer shadows. Shadows cast by the sun on landscape surfaces and embedded in images are a major problem when making relief presentations. The higher the terrain, the denser and more obscuring the shadows become. A compounding problem is the light direction on geospatial images, typically from the southeast (lower right), which places shadows on northwest (upper left) facing slopes when images are north-oriented. The result is "terrain inversion": Mountains appear as valleys, and vice versa.

Removing embedded shadows from images is not feasible in mountainous terrain with the densest shadows - more damage than good results from image editing procedures. However, on images with low relief or limited areas of high relief, shadow removal is a workable option. The best images to use are those taken around the summer solstice when the sun is highest and shadows are shortest. After removing the shadows from the geospatial image, one can then merge the image with conventional shaded relief to create a hybrid product with positive traits of both; shaded relief that reads properly, 
plus realistic and attractive image textures (Figure 11, right).

The NPS removes, or at least neutralizes, embedded shadows from images using two Adobe Photoshop procedures. The first procedure works best on images with light or moderate shadow densities. It involves lightening the shadows with a Brightness/Contrast adjustment. To select the shadows to apply this adjustment, one must first create a shaded relief mask from a DEM of the same area that matches the sun angle and azimuth of the image. The metadata file accompanying Landsat 8 images provides this information.

The second procedure applies to images with bold shadows that completely obscure land surface textures. The NPS selects these shadows with Photoshop's Magic Wand tool and uses Content Aware Fill to automatically replace them with textures borrowed from elsewhere on the image. This process is potentially inaccurate and misleading. After merging a shaded relief with the doctored image, however, the brightly illuminated slopes on the relief completely cover image areas that were formerly shadows (Figure 11). Printing the geospatial image lightly when merged with shaded relief also ameliorates this problem. The objective is to show a hint of image detail on all but the steepest slopes.

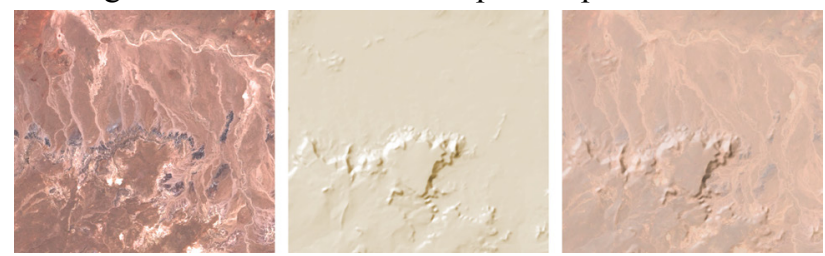

Fig. 11. Petrified Forest National Monument, Arizona. (Left) A Landsat 8 image with embedded cast shadows. (Center) Shaded relief created from a DEM of the same area. (Right) Merged Landsat 8 and shaded relief.

\section{Conclusions}

The relief found on today's NPS maps reflects an evolving array of styles and techniques. Deciding which style of relief to use depends on many factors, including available data, terrain and land cover characteristics, map purpose, and time constraints. For example, creating an elaborate natural-color relief of Great Smoky Mountains National Park in the southern Appalachians would serve no useful purpose because little land cover variation exists - the park is mostly wooded from valley bottom to ridge top. A basic shaded relief perhaps combined with texture shading case would suffice in this case.

Recently developed styles of relief presentation have not necessarily supplanted earlier styles. While the 1970s and 80 s were the heyday of manual relief shading, the NPS still applies manual touchups to digital reliefs-using Photoshop and a Wacom tablet - to meet design needs not possible through automated means. For example, the Kenai Fjords map (Figure 5) has a hand-drawn ocean bottom because digital bathymetric data was not yet available for that area at the time of map production. And some newer maps combine relief presentation styles.
Canyonlands National Park, Utah, for example, employs three of the styles described in this chapter (Figure 12).

On the whole, relief presentation on NPS visitor maps has changed dramatically since the Unigrid brochure program began in 1977, and continues to evolve. As software and data improve, so too will the relief presentations on park maps.

\section{References}

Brown, L., 2014. Texture Shading: A New Technique for Depicting Terrain Relief [presentation], 9th ICA Mountain Cartography Workshop, Banff, Canada. https://app.box.com/textureshading

Hanna, J. 1988. Ups and Downs of Shaded Relief, Courier: Newsmagazine of the National Park Service, (11), 23.

Imhof, E. 1982. Cartographic Relief Presentation. Edited by H. J. Steward. Berlin: de Gruyter, 172.

Leonowicz, A., Jenny, B., and Hurni, L. 2010. Terrain Sculptor: Generalizing Terrain Models for Relief Shading, Cartographic Perspectives, (67), 51-60.

Patterson. T. 2002. Getting Real: Reflecting on the New Look of National Park Service Maps, Cartographic Perspectives, (43), 43-56.

Patterson, T. and Kelso, N. 2004. Hal Shelton Revisited: Designing and Producing Natural-Color Maps with Satellite Land Cover Data, Cartographic Perspectives, (47), 28-55.

Patterson, T. and Jenny, B. 2010. Shaded Relief Archive [accessed 2014]. December

6 , reliefs.html http://www.shadedreliefarchive.com/nps- 